\title{
INVESTIGACIÓN
}

Recibido: 27/06/2019 --- Aceptado: 12/08/2019 --- Publicado: 15/06/2020

\section{LAS REPRESENTACIONES DE LA MUJER DE TALLA GRANDE EN LA PUBLICIDAD: CASO FOREVER 21}

\author{
Plus-size women's representations in advertising: Forever 21 case
}

\begin{abstract}
(D) 공 Noemí Vargas Ortiz¹. Universidad Nacional Autónoma de México. México. vargasortiznoemi@gmail.com
\end{abstract}

\section{RESUMEN}

La representación física de la mujer es un tema trascendental en la publicidad. Algunas marcas han apostado por modelos atípicas, que muestran lo que parece diferente, pero es común y real. Dentro de ellas se encuentran las modelos de talla grande y esta investigación analiza sus representaciones en la publicidad de la marca estadounidense Forever 21. El objetivo es determinar si se ha promovido, aceptado y valorado el concepto de talla grande como una nueva representación de belleza. Se procede con una investigación en dos fases. La primera identifica las representaciones generales de la mujer de talla grande en la publicidad, explicando cómo se han incorporado nuevos roles. Para ello se recurre a diversas fuentes documentales para observar cómo la publicidad es promotora de estereotipos y estilos de vida. La segunda parte indaga en la publicidad de Forever 21, en su cuenta oficial de Instagram, con un análisis hermenéutico basado en el modelo de Julio Amador Bech, al que se agregan cuestiones de tipografía, planos, ángulos y tomas. Se tomaron en cuenta las imágenes publicadas durante tres meses, del 1 de marzo al 30 de mayo de 2018, observando que sólo 26 imágenes de las 682 publicadas incluyen modelos de talla grande. Esto representa un 3,8\% de los posts. Sólo se eligieron las imágenes donde aparecen, a la vez, las modelos La'Tecia Thomas (de talla grande) y Fiona Barron. Esto permite, a simple vista, hacer una comparación, y nos sugiere un análisis muy rico, inédito y original.

PALABRAS CLAVE: publicidad - mujer - redes sociales - Instagram representación - estereotipos - talla grande - cánones de belleza - Forever 21.

\section{ABSTRACT}

The physical representation of women is a major issue in advertising. Some brands have opted for atypical models, which show what seems different but is common and real. Among them are the plus-size models and this piece of research analyzes

\footnotetext{
${ }^{1}$ Noemí Vargas Ortiz: Egresada de la Licenciatura en Ciencias de la Comunicación en la Facultad de Ciencias Políticas y Sociales (FCPyS) de la Universidad Nacional Autónoma de México (UNAM).
} 
their representations in the advertising of the American brand Forever 21. The goal is to determine if the concept of large size has been promoted, accepted and valued as a new representation of beauty. We proceed with a two-phase piece of research. The first identifies the general representations of plus-size women in advertising, explaining how new roles have been incorporated. For this, various documentary sources are used to observe how advertising promotes stereotypes and lifestyles. The second part explores Forever 21 advertising, on its official Instagram account, with a hermeneutical analysis based on Julio Amador Bech model, to which typography, shots, angles and takes are added. The images published for three months, from March 1 to May 30, 2018, were taken into account, noting that only 26 images out of the 682 published included plus-size models. This represents $3.8 \%$ of posts. Only the images where the models La'Tecia Thomas (plus size) and Fiona Barron appear at the same time were chosen. This allows us, at first glance, to make a comparison and suggests to us a very rich, unpublished and original analysis.

KEYWORDS: advertising - woman - social networks - Instagram - representation stereotypes - plus size - beauty canons - Forever 21.

\section{AS REPRESENTAÇÕES DA MULHER PLUS SIZE NA PUBLICIDADE: CASO FOREVER 21}

\section{RESUMO}

A representação física da mulher é um tema transcendental na publicidade. Algumas marcas tem apostado por modelos atípicas, que mostram o que parece diferente, mas é cotidiano e real. Dentro delas estão as modelos plus size e esta pesquisa analisa suas representações na publicidade da marca estadunidense Forever 21. O objetivo é determinar se tem promovido, aceito e valorizado o conceito de plus size como uma nova representação de beleza. Se procede com uma pesquisa em duas fases. A primeira identifica as representações gerais da mulher plus size na publicidade, explicando como tem se incorporado, novos papéis. Para isto recorremos a diversas fontes documentais para observar como a publicidade é promotora de estereótipos e estilos de vida. A segunda parte investiga na publicidade da Forever 21, na sua conta oficial de Instagram, com uma análise hermenêutica baseada no modelo de Julio Amador Bech, no qual se adicionam questões de tipografia, planos, ângulos e tomadas. Foi levado em consideração as imagens publicadas durante três meses, de 1 de março a 30 de maio de 2018, observando que somente 26 imagens das 682 publicadas incluíram modelos plus size. Isto representa um total de $3,8 \%$ dos posts. Somente foram escolhidas as imagens onde aparecem, ao mesmo tempo, as modelos La'Tecia Thomas (plus size) e Fiona Barron. Isto permite, à simples vista, fazer uma comparação, e nos sugere uma análise muito rica, inédita e original.

PALAVRAS CHAVE: publicidade - mulher - redes sociais - Instagram representação - estereótipos - plus size - cãnones da beleza - Forever 21. 


\section{Cómo citar el artículo:}

Vargas Ortiz, N. (2020). Las representaciones de la mujer de talla grande en la publicidad: caso Forever 21. [Plus-size women's representations in advertising: Forever 21 case]. Vivat Academia. Revista de Comunicación, (151), 1-24. doi: http:// doi.org/10.15178/va.2020.151.1-24 Recuperado de http://www.vivatacademia.net/index.php/vivat/article/view/1203

\section{INTRODUCCIÓN}

El concepto de belleza femenina ha tenido diversos enfoques a través de los años, dependiendo del contexto histórico en el que se encuentren las mujeres. Durante mucho tiempo, se ha vinculado estrictamente con características como la delgadez y la juventud. Sin embargo, las mujeres han pasado por muchos cambios sociales que las llevaron a exigir una representación real. Pasaron de parecer completamente dependientes del hombre y centrar sus aspiraciones en el ámbito familiar, a ser independientes, con participación real en el ámbito educativo y laboral, para lograr un contexto más favorable y el merecido empoderamiento.

Concretamente, en los contenidos publicitarios dirigidos a mujeres, "no sólo deben verse jóvenes y radiantes, sino que también deben estar actualizadas en cuanto a su aspecto, ya sea el corte de cabello o la ropa" (Hernández Suriano, 2003). La moda es un factor clave en la percepción de belleza y en los anuncios publicitarios suele aconsejarse la compra de productos que abarcan ropa, accesorios, maquillaje, etc. Aunque muchas mujeres imitan modelos, "también se limitan a elegir aquello que vaya con su personalidad, seleccionan el tipo de maquillaje, el modelo de peinado, el vestido, escogen, eliminan, retienen lo que corresponde a su personalidad, a sus expectativas, a sus gustos" (Lipovetsky, 1999, p. 155). Esto implica que no todas las mujeres estén conformes con los ideales de belleza representados en los medios, en gran parte porque los consideran irreales y no se identifican con ellos (Mora y Padilla, 2018; Padilla y Oliver, 2018).

La idea de idolatrar a alguien que se considera como un referente se muestra, con todos sus peligros, en la etapa de adolescencia. En esta etapa, las personas están buscando su identidad y resulta gratificante parecerse a alguien a quien se admira. Cuando la edad otorga madurez y las mujeres se aceptan tal y como son, resaltan otras cualidades reales, como la inteligencia, el talento o la resiliencia. Por lo anterior, el ideal actual de belleza femenina representado a través de la publicidad se ha diversificado, mostrando distintas mujeres que ya no cumplen con características estéticas como la delgadez, la altura y la juventud (Pellicer, 2018; Tapia, Rajas y Martín, 2018; Tapia y Del Toro, 2019). El valor central es mostrar que existen diferentes tipos de belleza.

Los ideales de belleza femenina representados en la publicidad están cambiando; o por lo menos, se están llevando a cabo pasos positivos hacia la ruptura de estereotipos tradicionales. Un ejemplo de ello es la inclusión de modelos atípicas, 
dentro de las cuales se encuentran las modelos de talla grande: una forma de representación femenina que se ajusta al contexto fisiológico de muchas mujeres españolas. Con la apertura a nuevas representaciones femeninas, muchas marcas se han visto en la necesidad de mostrar la belleza desde una perspectiva diferente; y al mismo tiempo, real, de acuerdo con el cuerpo de la mujer. De esta forma obtienen algunos beneficios, como mostrarse empáticas con las consumidoras y acaparar un segmento atractivo para las compras.

Las representaciones comunes de madre, esposa y ama de casa se han ido fragmentando, al igual que los estereotipos de belleza femenina representados en la publicidad y en otros medios de comunicación (Padilla y Semova, 2014; Padilla, 2016; Bernárdez y Moreno, 2017; Espizua y Padilla, 2017; Jivkova, Requeijo y Padilla, 2017; Ortiz García, 2017; Bernárdez y Padilla, 2018; Bernárdez y Serrano, 2018). Se han creado otras representaciones, que se adaptan más al contexto sociocultural de la mujer. Precisamente, la búsqueda de publicidad con modelos atípicas dio pie a la existencia de las modelos de talla grande. Muchas marcas comenzaron a promocionar sus productos con este tipo de mujeres y el propósito de generar un contacto más directo con sus clientes, aumentar sus ventas y mostrar una imagen incluyente; entre ellas, la marca estadounidense textil Forever 21.

Para muchas marcas crear un vínculo con sus consumidoras se ha convertido en un aspecto fundamental. El hecho de que las consumidoras se sientan identificadas con un patrón de belleza mucho más real, ajustado a sus características físicas, puede ayudar a incrementar las ventas. Asimismo, en el mundo de la moda se registran cambios y cuestionamientos a los estándares de belleza, y las modelos de talla grande no son más que una diversificación de las representaciones de belleza emitidas en la publicidad. La inclusión de la representación de la mujer de "talla grande" o plus size en la publicidad se creó hace algunas décadas por la industria textil estadounidense. “Desde finales de 1800 y principios de 1900 existieron actrices representativas en esta industria, por ejemplo, Lillian Russell y Elsie Scheel, quienes estaban lejos del ideal de belleza que se tiene hoy en día" (El Mercurio, 2015).

Sin embargo, el concepto no ha tenido tanta importancia hasta hace algunos años. En gran medida porque se utilizaba para referirse a las prendas de ropa, para determinarlas como tallas grandes; pero no para indicar que se trataba de una modelo o una persona común. En la actualidad, el concepto se ha personalizado en tal grado que las modelos de talla grande resultan comunes para algunas marcas: "Fue a comienzos del año 2000 cuando algunas marcas empezaron a desarrollar de forma más evidente moda para mujeres con figuras más reales, con cuerpo de talla grande, tal es el caso de la tienda de ropa Forever 21" (El Mercurio, 2015).

Incluso, se han realizado algunos eventos importantes donde el tema principal es la representación de este nuevo concepto. "En 2016 se organizó en forma paralela a la Semana de la Moda de Nueva York, un evento llamado "Full Figured Fashion Week" ("La semana de la moda voluptuosa"), que mostró desfiles con colecciones de moda en las que las prendas superaban la talla 46" (Economía y Negocios, 2015). A pesar

Vivat Academia. Revista de Comunicación. 15 junio 2020 /15 septiembre 2020, nº 151, 1-24 
de que el estereotipo de belleza femenina continúa privilegiando los cuerpos delgados, la aceptación de este tipo de modelos se ha dado de tal forma que, durante 2017, “Ashley Graham se convirtió la primera modelo plus size que se cuela a la lista de las 10 mejor pagadas de la revista Forbes" (Milenio Digital, 2017).

Del mismo modo, durante los últimos años, las modelos plus size han provocado un giro mediático muy fuerte, en parte gracias a las redes sociales, donde la mayoría de las mujeres reflejan la aceptación y exigen la integración de este tipo de modelos. Generalmente, tienen una talla que ronda entre la 40 y 48 española $(8$ y 16 estadounidense) y gozan de una altura promedio de 1,72 metros. La novedad no radica en hablar de mujeres de talla grande y marcas que integren las tallas grandes a sus catálogos, sino de jóvenes de talla grande y ropa juvenil de talla grande. Socialmente está aceptado que una mujer adulta y con hijos pueda tener sobrepeso. Los embarazos se pueden ver como una justificación. Muy por el contrario, una mujer joven y sin hijos debe estar delgada y lamentablemente, la sociedad condena que no sea así.

Las mujeres de cuerpos normales y robustos también quieren verse bien, vestir a la moda y acorde a la edad que tienen. Muchas veces encuentran ropa de su talla, pero con diseños aseñorados, anticuados, envejecidos. Forever 21 quiso romper con esta tendencia, ofreciendo la misma ropa en todas las tallas. No había diseños "normales" y diseños de "talla grande"; sino que planteó ofrecer la misma prenda para todo tipo de mujeres. Así, lanzó la categoría de talla grande o plus size en 2009. Desde entonces, ha propuesto importantes avances, añadiendo accesorios y lencería. Sin embargo, no fue hasta hace un par de años, cuando comenzó a dar más importancia a esta categoría promoviendo sus prendas con modelos de talla grande por medio de sus redes sociales. A través de su cuenta oficial de Instagram @forever21, la marca publicó, durante la temporada primavera-verano de 2018, una serie de fotografías donde la modelo de talla grande La'Tecia Thomas y la modelo convencional Fiona Barron aparecían juntas, vistiendo las mismas prendas.

La marca creada por el coreano Do Won Chang y su mujer Jin Sook Chang les hace encabezar el número 222 de la lista Forbes 400 de los más ricos en Estados Unidos, con un patrimonio cercano a los 3,000 millones (Álvarez, 2016). Forever 21 se caracteriza por ofrecer productos de moda, en su gran mayoría ropa, pero también accesorios y productos de belleza. La tienda ofrece ropa casual como blusas, playeras, pantalones, shorts, etc.; y también se pueden encontrar prendas elegantes como vestidos, faldas o blazers. Tanto en el buscador como en sus redes sociales, la marca se muestra incluyente al dar a conocer prendas dirigidas a mujeres de talla grande. En su buscador oficial cuenta con una sección dirigida específicamente para mujeres con estas características.

La fanpage de Forever 21 así como su cuenta de Instagram han sido un factor clave para dar a conocer la integración de las modelos de talla grande en la difusión de los productos de la marca. Los usuarios pueden interactuar fácilmente porque dichos 
sitios invitan a conocer el producto de una forma más sutil, sin estar directamente buscando algún producto, pero estando al pendiente de cualquier novedad.

Asimismo, es trascendental mencionar que un gran número de investigadores se han interesado por la publicidad con una visión igualitaria de género y en los últimos años sobre referentes estéticos. Se parte del siglo XIX, época en la cual se ligaba directamente la feminidad con el consumo, al ser un hábito femenino comprar cosas que expresaran el estatus social del marido" (Cuevas Barnerousse, 2009).

Por su parte, Lipovetsky (1999) narra y analiza los procesos de transformación y de confluencia de los roles de género tradicionales y modernos en la vida de las mujeres de hoy, utilizando el termino tercera mujer para referirse a la nueva figura femenina que expresa un avance sustancial en diferentes ámbitos, entre los que destacan el educativo y el laboral, de tal forma que "a partir del siglo XX comenzó la gran revolución femenina" (Camps, 2000).

El siglo XXI es un siglo de grandes perspectivas para las mujeres, por lo que es importante conocer cómo esta se refleja en los medios, "pues es un indicador de su realidad social" (Martín Casado, 2009). Los cambios socioculturales se ven reflejados en la forma como se representa en la publicidad, creando nuevas representaciones que reflejan una mujer con igualdad de oportunidades respecto al hombre.

"Los estereotipos se han reconfigurado y junto a las figuras tradicionales se generan otras" (García Calderón, 2015, p. 166), ahora no sólo se representa una mujer maternal, también una mujer profesional, con trabajo y poder en la toma de decisiones. Por ello surgen nuevos contenidos que se adaptan al contexto actual de las mujeres. Carola García (2015) menciona que la imagen de la mujer moderna se presenta como protagonista en los anuncios, creando el termino mujer alfa: una mujer independiente económicamente, con seguridad, triunfadora y dedica su tiempo a buscar su realización profesional.

Una multitud de autores han centrado sus investigaciones en analizar cómo está representada la mujer en los diversos medios. Berger (1975) explicó sobre los estereotipos que "lo que vemos queda a nuestro alcance, aunque no necesariamente al alcance de nuestro brazo", es decir, no porque exista algo todos lo podemos tener.

Asimismo, el concepto de belleza también forma parte de los tópicos a investigar en el ámbito publicitario. Éste ha tenido diversos enfoques a través de los años ya que "los valores estéticos guardan una estrecha relación con las configuraciones históricas, sociales, económicas y culturales" (Walzer, 2008, p. 18), por ejemplo, "durante el Renacimiento un cuerpo bello era aquel de forma redonda y exuberante, de vientre poderoso y caderas voluptuosas" (Cabrera García-Ochoa, 2010).

Actualmente, el concepto de belleza suele ligarse con la indumentaria. Suriano (2010) menciona que "las mujeres no sólo deben verse jóvenes y radiantes, también deben estar actualizadas en cuanto a su aspecto, ya sea el corte de cabello o la 
ropa". Por su parte, Bernárdez (2000) menciona que la publicidad es un medio amoral, que utiliza hasta la saciedad la representación del cuerpo para cualquier cosa (Bernárdez, 2000). En este proceso, lo des-corporeiza, lo des-humaniza y desexualiza, acercándolo a ser un objeto, valorado por sus cualidades estéticas (Bernárdez, 2000).

Ruth Gómez de Travesedo-Rojas y Ana Almansa-Martínez (2017) analizaron la forma en que la mujer está representada en la publicidad incluida en las revistas femeninas comerciales de alta gama en España. El estudio aplica el enfoque de análisis de contenido de los cuatro títulos principales en 2014: Cosmopolitan, Glamour, Elle y Vogue. Los datos demostraron que el cuerpo femenino se utiliza principalmente como maniquí en el escaparate de una tienda de moda. Mendoza Cuellar (2012) también estudió la publicidad y su rol en la formación de estereotipos de género y concluyó que las leyes pueden condenar la publicidad ilícita, pero no sustituyen a los valores culturales, que son igualmente peligrosos. Poco después, Carretero (2014) asimiló la publicidad sexista, desde la pasividad y tolerancia social frente a anuncios que cosifican a las mujeres y atentan contra su dignidad.

En la misma línea, Bernárdez (2009) estudió las mujeres en la publicidad, como muñecas, entre la materia artificial y la carne. Explicaba que el estereotipo de la mujer muñeca y la idealización que este modelo ha supuesto para las mujeres reales un modelo inalcanzable en la vida personal y se ha erigido como el caballo de batalla del pensamiento feminista, en aras de pensar en la identidad de las mujeres desde la corporalidad y la materialidad del cuerpo (Bernárdez, 2009 y 2015).

Este tipo de modelos inalcanzables, con bellezas poco típicas, pero completamente aspiracionales, han provocado que muchas mujeres sólo tomen en cuenta los ideales de belleza presentados en los medios y se proponen cumplirlos sin importar recurrir a cirugías estéticas. "En las últimas décadas también la belleza es tratada desde la perspectiva medica: se presentan las novedades en cuidado del cutis, temas como el Botox, los tratamientos anticelulitis, el modelado del cuerpo y las cirugías plásticas" (García Calderón, 2015, p. 157).

Sin embargo, otras mujeres desafían el modelo inalcanzable que la publicidad intenta transmitir, muestran su desacuerdo y exigen representaciones mucho más reales que se ajusten a su fisionomía. La publicidad no crea comportamientos sociales, si no que va a la vanguardia de la moda, de las nuevas ideas y de las nuevas costumbres, y lo único que hace es propagarlas (Ferrer Roselló, 1994; Philips, 1997), por lo que se ajusta a estas peticiones mostrando empatía con las consumidoras.

Es por lo que, esta investigación se centra en describir y analizar una de las nuevas representaciones vista con cada vez más frecuencia en la publicidad: las representaciones de la mujer de talla grande o plus size, promovidas a partir de año 2000 cuando algunas marcas empezaron a desarrollar de forma más evidente moda para mujeres con figuras de talla grande (Economía y Negocios, 2017). 
Por otra parte, es importante mencionar que actualmente "el mundo digital afecta a todas las parcelas del trabajo y de las actividades humanas" (Padilla y Semova, 2014) y resulta trascendental tomar en cuenta la publicidad emitida a través de Internet. Dentro de Internet, "las redes sociales han transformado las formas de comunicación interpersonales y los hábitos de consumo" (Padilla y Semova, 2014).

\section{OBJETIVOS}

El objetivo general de esta investigación es analizar las representaciones de la mujer de talla grande, emitidas en la publicidad de la marca Forever 21, para determinar si se ha promovido, aceptado y valorado este concepto de talla grande como una nueva representación de belleza.

Este objetivo principal abarca los siguientes objetivos secundarios:

1) Analizar el contexto sociocultural de la mujer urbana.

2) Identificar las diferentes representaciones de la mujer en la publicidad, en especial la mujer de talla grande.

3) Analizar la relación de la publicidad digital de la marca Forever 21 enfocada a las mujeres de talla grande.

\section{METODOLOGÍA}

Esta investigación contiene dos fases. La primera consiste en identificar las representaciones de la mujer de talla grande en la publicidad, explicando cómo se han incorporado nuevos roles femeninos que representan a la mujer de acuerdo con las modificaciones socioculturales que ha sufrido. Para identificar estas representaciones se recurrirá a diversas fuentes de investigación documental para observar cómo la publicidad es promotora de estereotipos y estilos de vida, transmitiendo cánones de belleza femenina a través de los medios de comunicación.

La segunda parte se refiere a la indagación de publicidad de la marca Forever 21 en su cuenta oficial de Instagram. Esta publicidad integra las modelos de talla grande. Para determinar la relación que tiene la publicidad de la marca Forever 21 enfocada a mujeres de talla grande con la realidad, se realiza un análisis hermenéutico basado en el modelo de Julio Amador Bech, que propone en su libro El significado de la obra de arte: conceptos básicos para la interpretación de las artes visuales. Al modelo se agregarán algunas cuestiones referentes a la tipografía, así como planos, ángulos y tomas, ya que se consideran apropiadas para un análisis de identificación en la imagen. Dicho modelo se plantea de la siguiente manera:

\section{DIMENSIÓN FORMAL}

1) Identificar seres y objetos.
a) Forma.
b) Color.
c) Tono o luminosidad. 
d) Cualidades materiales.

e) Composición.

f) Tipografía.

g) Planos, ángulos y tomas.

2) Identificar la expresión de los elementos.

a) Apariencia física del cuerpo, movimientos y gestos corporales.

b) Aspectos que configuran la atmosfera y la escenografía.

3) Identificación y clasificación de motivos. Identificar las formas.

DIMENSIÓN SIMBÓLICA

1) Simbolismo de la forma.

2) Simbolismo del color.

3) Simbolismo de la luz.

4) Simbolismo de la materia.

\section{DIMENSIÓN NARRATIVA}

1) Imagen, elementos, temas.

a) Definir si es imagen figurativa o abstracta.

b) Distinguir elementos: personajes, acciones, situaciones.

c) Reconocer de un tema.

2) Análisis en tres pasos.

a) Análisis estructural (acciones y situaciones de los personajes).

b) Análisis histórico-cultural (momento en que sale la campaña).

c) Análisis de las funciones sociales narrativas míticas.

También es importante mencionar que se tomaron en cuenta las imágenes publicadas durante tres meses, del 1 de marzo al 30 de mayo de 2018, observando que sólo 26 imágenes de las 682 publicadas en la cuenta oficial de la marca incluyen modelos de talla grande. Esto representa un 3,8\% de los posts. Asimismo, se eligieron para el análisis hermenéutico imágenes con características similares, donde aparecen las modelos La'Tecia Thomas (@lateciat, de nacionalidad australiana) y Fiona Barron (@fiona.bl, de nacionalidad mexicana); y sólo primera es considerada de talla grande. La marca las presenta con ropa similar y posiciones análogas. Esto permite, a simple vista, hacer una comparación, y nos sugiere un análisis muy rico, inédito y original.

La marca Forever 21 fue elegida porque ha desarrollado estrategias de mercado dirigidas a mujeres que rompen con el estereotipo de belleza tradicional. Es decir, que no son de talla pequeña, esbeltas o delgadas. Asimismo, se eligió Instagram tomando en cuenta la relevancia y el uso de la red social entre los jóvenes y millennials, que hace necesario investigar la interacción que generan las marcas con el consumidor: "Las redes sociales se erigen como el espacio idóneo para observar, para investigar el mercado, para conocer las inquietudes de los usuarios" (Fernández et al., 2018 , p. 25). Instagram, la red social de fotografías, es la tercera red más usada en España, sólo después de Facebook y de WhatsApp (Sánchez, 2018) y “ha tenido 
mayor crecimiento logrando duplicar el número de usuarios en sólo dos años" (Mejía, 2019). Además, el rango de edad de 18 a 34 años es el que prevalece en los usuarios y se ajusta con el target al que se dirige la marca.

\section{RESULTADOS}

\subsection{Análisis hermenéutico de la publicidad de Forever 21 en Instagram}

En este apartado se aplica el enfoque hermenéutico de la imagen al análisis del mensaje publicitario, tomando en cuenta el modelo que plantea Julio Amador Bech (2001), quien a su vez retoma la metodología de Erwin Ponofsky para el estudio de la obra de arte. Una imagen es una construcción simbólica, creada por la mente humana para representar cosas que no están presentes. Para interpretar estos mensajes, Amador (2001) propone tres dimensiones del significado de la imagen: la dimensión formal, la dimensión del signo visual y la dimensión narrativa; complementándose todas por el análisis histórico-cultural.

A partir de las tres dimensiones propuestas por Julio Amador (2001), así como las aportaciones de la doctora Verónica Servín (2002) y algunas cuestiones referentes a planos, tomas y ángulos, se realiza el análisis hermenéutico de algunas imágenes publicadas por la marca Forever 21 en su cuenta de Instagram, durante la temporada primavera-verano de 2018. Es importante mencionar que en este apartado se ve a la tecnología como un aliado confiable tanto para la marca como para el segmento, ya que las redes sociales han jugado un papel fundamental en la revolución de la industria de la moda de talla grande o plus size.

En las siguientes líneas, se presenta una de las fotografías con su análisis hermenéutico tomando en cuenta los ítems contemplados en el marco metodológico. Posteriormente, aparecen las cuatro fotografías restantes sin análisis hermenéutico ya que por la extensión, no es posible reproducir el análisis completo, pero sí los resultados finales de todas las fotografías. 


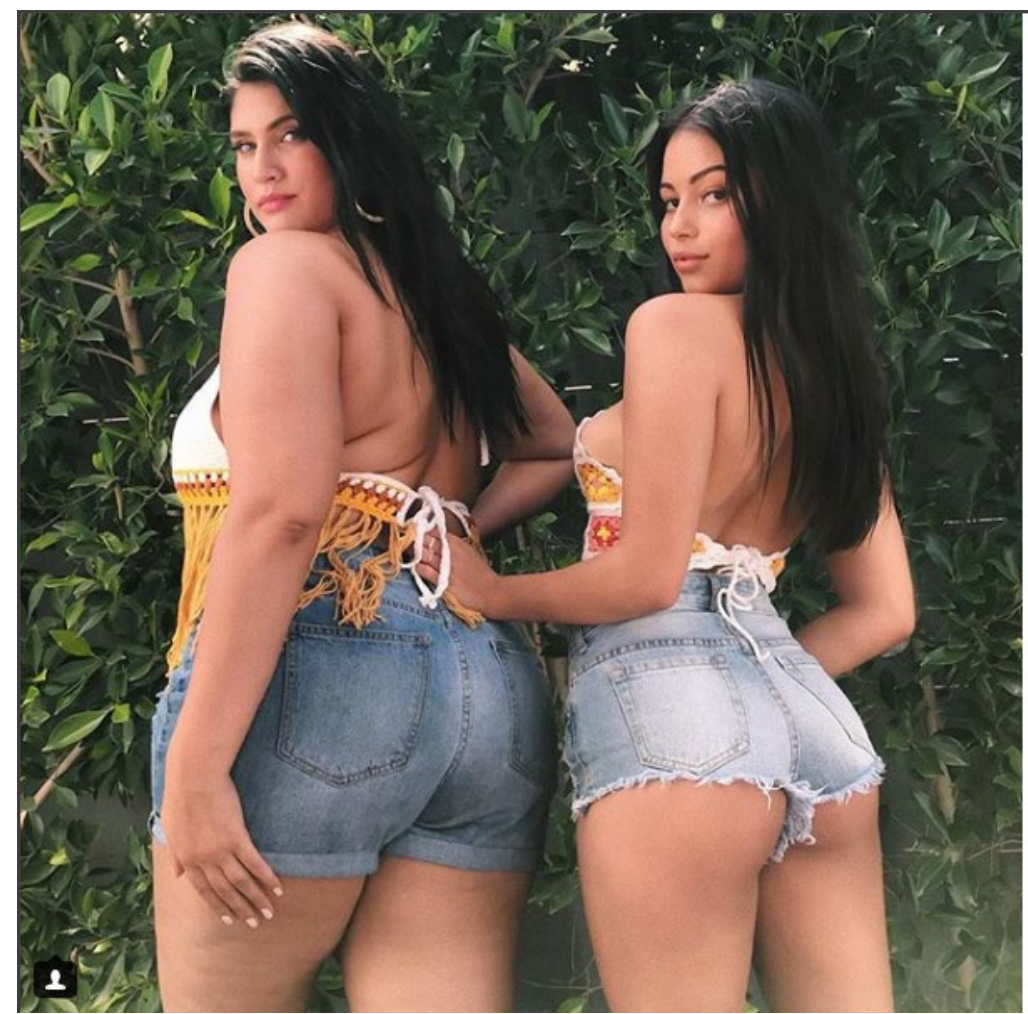

(21) forever21 $* \cdot$ Siguiendo

forever21 Turnin' up the heat with @lateciat \& @fiona.bl @: check out our stories to for a lil' tease of what's to come! xo

Cargar más comentarios

meggiiie_@its_jennaaa

dashhaa._. Pull your shorts down aliviaking_ $\mathrm{Hi}$

ishytadutta2394@aaiswanimohan179 4 it is. Definir

meeshaism I want longer shorts for everyone. I have been looking for something that reaches mid thigh or above knees (for normal, plus whatever sizes). Can you guys upvote this so forever2 1 can hear me out. danielmaitai46 Nossa lindas

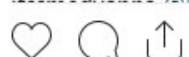

147,794 Me gusta

27 DE MARZO

Agrega un comentario.

Foto 1: fotografía y mensaje publicitario publicados el 27 de marzo de 2018, en la cuenta oficial de Instagram de la marca Forever 21.

Fuente: $\underline{\text { https:/ / www.instagram.com/p/Bg1yclal7Yx/ ?hl=es\&taken-by=forever21 }}$ (consultado el 20.10.2018).

\subsection{Dimensión formal del mensaje}

Identificación de seres y objetos. En el mensaje se observan dos mujeres. Ambas visten short azul y blusa blanca de motivos decorativos amarillos. También, aparecen las ramas de un árbol como fondo.

a) Forma. No se observan puntos, solamente aparecen algunas líneas horizontales, verticales y diagonales que forman las bolsas del short de ambas mujeres.

b) Color. Predomina el color verde de fondo, que forma parte de la naturaleza; posteriormente, el color carne de la piel de las mujeres, el azul de los shorts, el negro del cabello y el amarillo con blanco de las blusas. El amarillo puede connotar energía y llama la atención debido a que aparece en pocas cantidades, pero logra sobresalir.

c) Tono o luminosidad. Se percibe cierta luminosidad en la piel de las mujeres, sobre todo en la cara, en el brazo izquierdo y en las piernas. La luz se dirige hacia abajo y hacia adentro, al igual que la mirada de las féminas, esto provoca que dichas partes del cuerpo atraigan la atención.

d) Cualidades materiales. Se puede observar que el anuncio está realizado a través de la fotografía y publicado en un soporte digital. También es alargado, 
en forma de rectángulo horizontal. En cuanto a las cualidades materiales percibidas dentro de la imagen, se logra distinguir la piel lisa de ambas mujeres que connota sutileza, y en algunos elementos de la ropa, aparecen texturas con volumen, como las tiras colgantes de la blusa de la mujer del lado izquierdo, o las barbas del short de la mujer que aparece a la derecha, lo cual puede provocar cierta realeza.

e) Tipografía. En la frase “Turn' up the heat with @lateciat \& @fiona.bl check out our stories for a lil' tease of what's to come! Xo" (" $¡$ Aumenta el calor con @lateciat \& @fiona.bl echa un vistazo a nuestras historias para ver un poco de lo que está por venir! Xo") se utiliza una tipografía en cajas altas, perteneciente al grupo tipográfico Sans serif, trazos sin patines y uniformes. El espacio interlineal es mínimo, pero permite legibilidad. El color de la tipología es negro, con el que se representa elegancia. La fuente es legible, con un tamaño aproximado de 11 puntos.

También es importante mencionar que el texto está acompañado de emojis (ideogramas o caracteres usados en mensajes electrónicos). En este caso, a la mitad del texto, aparece un emoji de una cara sacando la lengua y al lado, corazones. Esto puede representar encanto por el producto que ofrece la marca.

f) Planos, ángulos y tomas. La imagen tiene un plano general medio (full shot) porque abarca la figura humana entera con espacio por arriba y por abajo, desde un ángulo contrapicado para representar un personaje psíquicamente fuerte, dominante o superior.

g) Composición. Las dos mujeres van vestidas con short y blusa, superpuestas sobre un fondo de hojas. Todos son elementos que integran la imagen y que se pueden medir en categoría de peso para generar equilibrio.

En cuanto al equilibrio de la forma, el peso se encuentra en la parte central de la imagen con figuras verticales, las cuales tienen más peso que las horizontales. En el equilibrio del color y tono, hay mayor peso en la parte inferior derecha y superior izquierda, donde aparecen tonalidades más claras. En el equilibrio de la ubicación, lo que está en la parte superior y lo que está a la derecha es más pesado. Por lo tanto, la cara de la modelo de la derecha tiene más peso en la imagen. En el equilibrio por tamaño, la figura con mayor tamaño es la mujer que aparece del lado izquierdo, y, por lo tanto, tiene mayor peso. Finalmente, en equilibrio por dirección, las formas centrípetas (de afuera hacia adentro) pesan menos que las centrífugas (de adentro hacia afuera) y en la imagen, las dos mujeres se colocan de forma centrífuga.

Con lo anterior se puede percibir una composición con equilibrio adecuado, debido a que la mujer del lado derecho tiene protagonismo por ubicación, pero la del lado izquierdo lo tiene por tamaño. Se puede decir que se manejan los componentes armónicamente y dan la idea de equidad entre las modelos. Por otro lado, y de acuerdo con la clasificación de Peninou (1976), la composición es axial ya que el objeto promocionado, en este caso la ropa, ocupa el lugar central de la imagen. 
Identificación de la expresión de los elementos. En la imagen podemos apreciar a las dos mujeres con caras atractivas, por lo que serán objeto de una elevada influencia en la percepción de la credibilidad. Es decir, sus palabras tendrán más validez que las de un sujeto no atractivo. Asimismo, y de acuerdo con la clasificación de Mark L. Knapp en cuanto a los estereotipos físicos temperamentales para identificar la personalidad respecto al aspecto físico, la mujer del lado izquierdo es endomorfa porque es el más gruesa. Implica que puede ser más conservadora, más bondadosa y simpática, de mejor naturaleza y más agradable; pero más dependiente de los demás y más confiada de en los otros.

La mujer que aparece del lado derecho es mesomorfa: fuerte y de mejor apariencia, joven y alta. Implica que puede ser más madura en su conducta y más segura de sí misma. Por otro lado, la estatura se asocia con el poder y la mujer que aparece del lado derecho tiene mayor poder en la imagen porque su cuerpo alto abarca más espacio. El color de piel de las dos mujeres es similar: un tono de piel claro, con la cara maquillada para resaltar los ojos, las mejillas y los labios de una forma sencilla y natural. El cabello de ambas es completamente negro, largo y lacio, lo cual representa feminidad y permite deducir que son mujeres con características físicas latinas.

La vestimenta de las dos mujeres es análoga: un short azul y blusa blanca con decoración amarilla, diferenciando que la mujer del lado izquierdo usa ropa menos escotada y aretes, los cuales pueden indican mayor grado de feminidad. En primera instancia, la ropa comunica feminidad, después juventud, estatus socioeconómico medio, personalidad atrevida, prendas para usarse con clima caluroso, en una situación informal y en una época actual. Al presentarse de una forma ajustada para ambas modelos, pero mostrando mayor parte de su cuerpo la modelo del lado derecho, la imagen puede representar la manera correcta de vestirse dependiendo del tipo de cuerpo que tenga una mujer.

Dentro de los movimientos del cuerpo, posturas y gestos corporales, se puede observar que la mujer del lado derecho pone su mano sobre la cintura de la mujer del lado izquierdo para expresar compañerismo y empatía. Del mismo modo, el brazo derecho de ambas está en su cintura para indicar feminidad e intentar agradar. Las dos mujeres tienen una postura de lado, pero dirigen su mirada intensa, un tanto provocativa y sensual hacia enfrente, con la cara seria y una ligera sonrisa. Indica que están posando y mirando hacia la cámara con sensualidad, feminidad y extroversión.

La imagen parece atractiva debido a la postura de las modelos, a simple vista su posición connota seguridad y firmeza. Su expresión corporal comunica una personalidad sexy por su mirada intensa. Finalmente, otra de las características de este apartado es definir los aspectos que configuraran la atmósfera o escenografía: el entorno es natural porque los personajes tienen como fondo ramas de árboles.

Identificación de los motivos: El motivo central del anuncio es mostrar que dos mujeres con cuerpos diferentes pueden vestirse con ropa similar y lucir a la moda. El 
único contacto físico que existe entre ambas entidades es a través de una mano. Sin embargo, transmiten igualdad y complicidad porque la ropa es muy pareja, con medidas diferentes adaptadas a cada tipo de cuerpo, pero con colores y texturas similares. La sintaxis visual nos remite a la vanidad femenina, el deseo de verse bien con ropa moderna.

\subsection{Dimensión simbólica del mensaje}

Este análisis pertenece a la segunda dimensión que propone Julio Amador, lo cual implica que formas primarias pueden traducirse a signos lingüísticos. Tomando en cuenta únicamente las figuras como signos, podemos decir que en la imagen aparecen mujeres, hojas de árbol y ropa. Ahora bien, tomando en cuenta estos mismos elementos, pero como símbolos, entonces se puede apuntar: las mujeres son modelos, las hojas de árbol son el fondo natural representado en la fotografía y la ropa (shorts y blusas) son el producto que la marca quiere dar a conocer.

Tomando en cuenta que las alegorías remiten a cualidades espirituales y morales que son difíciles de expresar, se puede mencionar que una modelo delgada y otra gruesa con la misma vestimenta serían igualdad, inclusión, seguridad.

a) Simbolismo de la forma. Como vimos en el análisis de la expresión, la forma de la ropa puede indicar quién, cómo y cuándo se puede usar cierta prenda. Por ejemplo: un short y blusa de tirantes durante la primavera, y un short muy escotado para mujeres delgadas.

Las modelos tienen características físicas diferentes en cuanto al cuerpo. La que aparece del lado derecho es delgada, alta y guapa. La del lado izquierdo es guapa y alta pero no es delgada; simboliza que la marca está siendo inclusiva con modelos de talla grande que no cumplen con todos los estándares habituales de belleza, actualmente establecidos.

b) Simbolismo del color. En la imagen se pueden encontrar colores primarios como el azul y amarillo, que equivalen a fenómenos primarios emotivos.

Por otro lado, el amarillo y el blanco son colores avanzantes que, aunque no son muy abundantes, sobresalen por la misma razón. El azul y el negro son colores fríos y retrocedientes que corresponden a procesos de desasimilación, pasividad y debilitación. Finalmente, el verde es el color de las plantas y representa la función de percepción, estimulación de los sentidos, vitalidad.

c) Simbolismo de la luz. La luz es identificada con el espíritu y las caras de los personajes tienen cierto grado de luminosidad que las hace frescas, juveniles, sustanciales.

d) Simbolismo de la materia. En la imagen se perciben materiales como la mezclilla, tela que ha tenido trascendencia en la moda debido a su gran importancia al romper barreras de estatus social. Sin importar el nivel socioeconómico y la edad, todas las personas cuentan con alguna prenda de mezclilla en su armario y de alguna forma, los jeans se han visto como símbolo de comodidad. 
Durante los últimos años surgieron algunos elementos para clasificar las prendas de mezclilla no sólo por género, sino también por edad. Por ejemplo, la apariencia de estar rasgada o rota simboliza modernidad.

En general, la ropa escotada connota que se debe usar con un clima caluroso. No obstante, en los últimos años, también representa modernidad y sensualidad. Pensemos que hace cien años, las mujeres no podían usar prendas tan escotadas como las que aparecen en la imagen.

Por otro lado, podemos traducir los símbolos en enunciados para tener más claro el mensaje:

- Las modelos tienen diferente apariencia física, una es delgada y la otra robusta.

- Las modelos usan ropa con características similares.

- Las modelos lucen seguras y sensuales.

- Las modelos usan de la marca Forever 21.

En resumen, simbólicamente, se puede evaluar que en la imagen aparecen dos modelos. Una de ellas es de talla grande, pero las dos visten ropa similar de la marca Forever 21, y muestran una apariencia segura y sexy. Se pretende que las consumidoras del producto (prendas de ropa) se sientan identificadas con ambas modelos, así como generar cierta empatía con las mujeres de talla grande, describiendo que las prendas también están hechas para ellas y lucen bien, de forma apropiada, acertada y juvenil.

\subsection{Dimensión narrativa}

La imagen es figurativa y cuenta con:

a) Personajes. Mujeres que son modelos.

b) Acciones. Están modelando.

c) Situaciones. De forma atractiva.

Para llevar a cabo el análisis narrativo se deben tomar en cuenta las siguientes perspectivas analíticas:

1) Análisis estructural. La modelo que aparece en el lado derecho está parada, con el cuerpo de lado, la mano derecha en su cintura, la mano izquierda en la cintura de su compañera, volteando la mirada hacia enfrente e inclinando su cara un poco hacia su hombro izquierdo.

La modelo de la izquierda está parada, con el cuerpo de lado, su mano derecha en su cintura y la mano izquierda dejándola caer sobre su pierna izquierda, llevando esta pierna un poco hacia adelante, con la cara inclinada hacia su hombro izquierdo pero la mirada hacia enfrente.

En este análisis también se toma en cuenta lo que es propio de la cultura. Entonces, es importante recordar las múltiples campañas sociales que se han realizado para combatir el acoso sexual y que uno de los principales motivos sea la ropa escotada de las mujeres. Esto no implica que deban dejar de usar 
este tipo de prendas. Sin embargo, esta situación, muchas veces, sí puede influir en la elección de compra.

2) Análisis histórico-cultural.

- Forever 21. La marca fue creada en Estados Unidos por el coreano Do Won Chang, en 1984. Rápidamente se fue expandiendo por todo el país y el resto del mundo. Actualmente, cuenta con más de 800 tiendas, siendo México el tercer país con más sucursales: más de 150.

La marca se caracteriza por ofrecer productos de moda, en su gran mayoría ropa, pero también accesorios y productos de belleza. Forever 21 lanzó la categoría plus size en 2009 y desde entonces, ha tenido importantes avances, añadiendo accesorios y lencería, además de promoverla a través de todas sus redes sociales.

- Personajes.

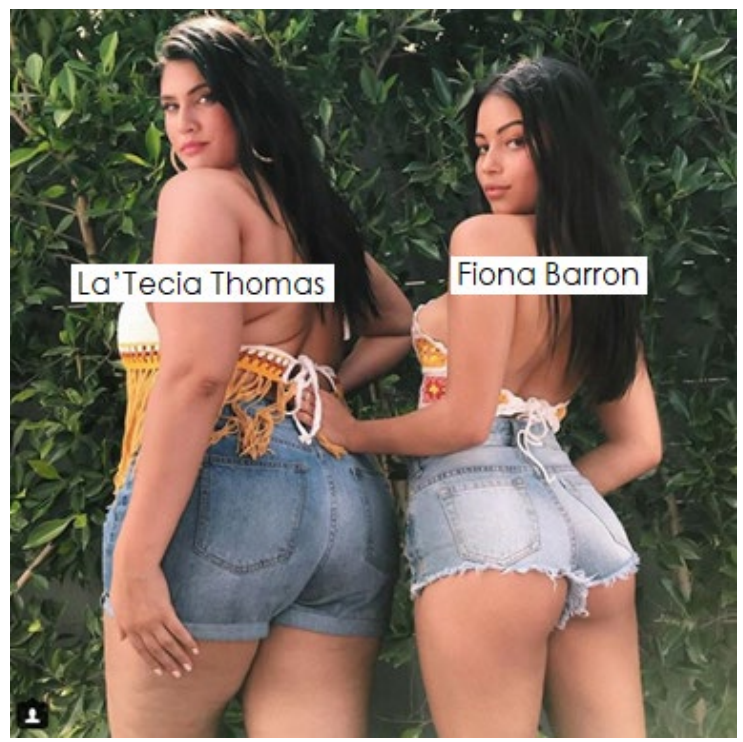

La'Tecia Thomas es una modelo reconocida por cambiar el paradigma de las fotografías de modelaje que muestran un antes y un después. Siempre que pensamos en este tipo de imágenes, nos remitimos a cambios que van de lo delgado a lo musculoso, o de lo gordo a lo delgado. Sin embargo, esta modelo australiana de 27 años subió a su cuenta de Instagram fotografías donde se describe su transformación de ser talla 6 a talla 16 . Además, argumenta que eso la ha ayudado a ser más feliz, a tener más autoestima y a luchar por empoderar a otras mujeres. La'Tecia es una de las modelos de talla grande que decidió cambiar el concepto de belleza, inspirada por la modelo Ashley Graham, destacando que la salud mental es tan importante como la salud física. La modelo que aparece en el lado derecho es la mexicana Fiona Barron, quien también es influencer de las redes sociales al tener más de 800,000 seguidores en su cuenta de Instagram, donde destacan sus fotos sensuales con cuerpo escultural.

- Imagen. Esta imagen fue insertada en la cuenta oficial de la marca Forever 21, el 27 de marzo de 2018. No cuenta con elementos que distingan o prueben 
dónde fue tomada. Es posible que haya sido realizada en Estados Unidos, país de origen de la marca, quizás también porque el texto está en inglés.

Sin embargo, sí tiene un acercamiento con la realidad mexicana, debido a que la modelo Fiona es de nacionalidad mexicana y ambas cuentan con características físicas distintivas de esta nacionalidad, como la piel morena y labios gruesos. También es cierto que muchas otras mujeres no cumplen con estándares de belleza establecidos como la delgadez, por lo cual, la modelo La'Tecia se remite a la imagen de muchas mujeres mexicanas de tallas grandes.

3) Análisis de las funciones sociales de las narrativas. Este mensaje publicitario se ha publicado otras cuatro veces en la cuenta de Instagram de Forever 21, no con las mismas prendas, pero sí las mismas modelos y otras características que se describirán más adelante.

\subsection{Reflexiones del análisis hermenéutico}

Con dicha información, se puede concluir que la imagen es ilustrativa ya que representa la integración de una nueva representación de la belleza en publicidad: las modelos de talla grande. La marca pretende comunicar a las consumidoras la aceptación e integración de este nuevo concepto, comparando la belleza estereotipada y la belleza que se acerca a muchas realidades mexicanas.

Al realizar el análisis histórico cultural también es importante conocer la percepción de las mujeres mexicanas urbanas en relación con este anuncio publicitario. Dicha percepción se puede obtener valorando los comentarios de las usuarias con características mexicanas, si son positivos, negativos o neutros; los temas más destacados; y algunas características físicas y biográficas de quienes comentaron.

En primera instancia, es importante mencionar que son muy pocos los hombres que publicaron en este post, la mayoría son mujeres jóvenes entre los 20 y 35 años; las que tienen fotos de su cara y cuerpo en su Instagram permiten observar que no todas tienen complexión de talla grande y aparentan un nivel socioeconómico medio. Entre los temas destacados se encuentran las comparaciones, donde las usuarias de identifican con las modelos, incluso algunas etiquetan a otra mujer y mencionan que las dos podrían tener características similares a las modelos. También aparecen comentarios positivos con aprobación para la marca por haber contemplado a la modelo de talla grande, haciendo halagos principalmente a la modelo. Son muy pocas las usuarias que escriben sobre el producto, pero las pocas referencias que aparecen son positivas. Es importante mencionar que muchas de las comparaciones se clasifican como neutras ya que las usuarias usan un tono sarcástico para burlarse de sí mismas al compararse, sobre todo con la modelo de talla grande.

Dentro de los comentarios negativos, se encuentran los que están en desacuerdo con que una mujer de talla grande sea modelo, siendo ésta discriminada. También hay comentarios negativos para la marca, con reclamos por mostrar una falsa igualdad y promover la obesidad. 


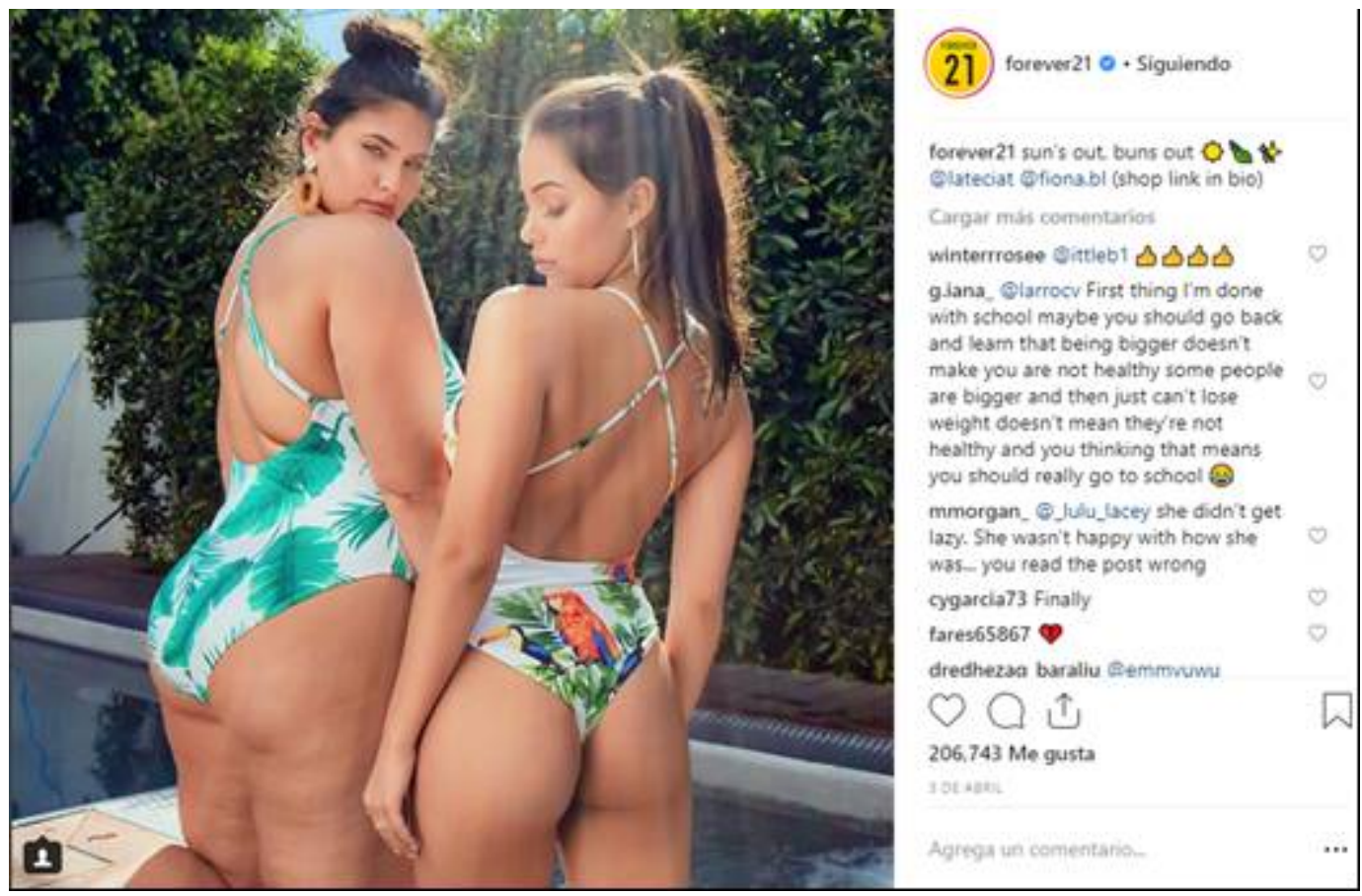

Foto 2: fotografía y mensaje publicitario publicados el 03 de abril de 2018, en la cuenta oficial de Instagram de la marca Forever 21.

Fuente: https://www.instagram.com/p/BhHWApaFEUn/?hl=es\&takenby=forever21 (consultado el 20.10.2018).

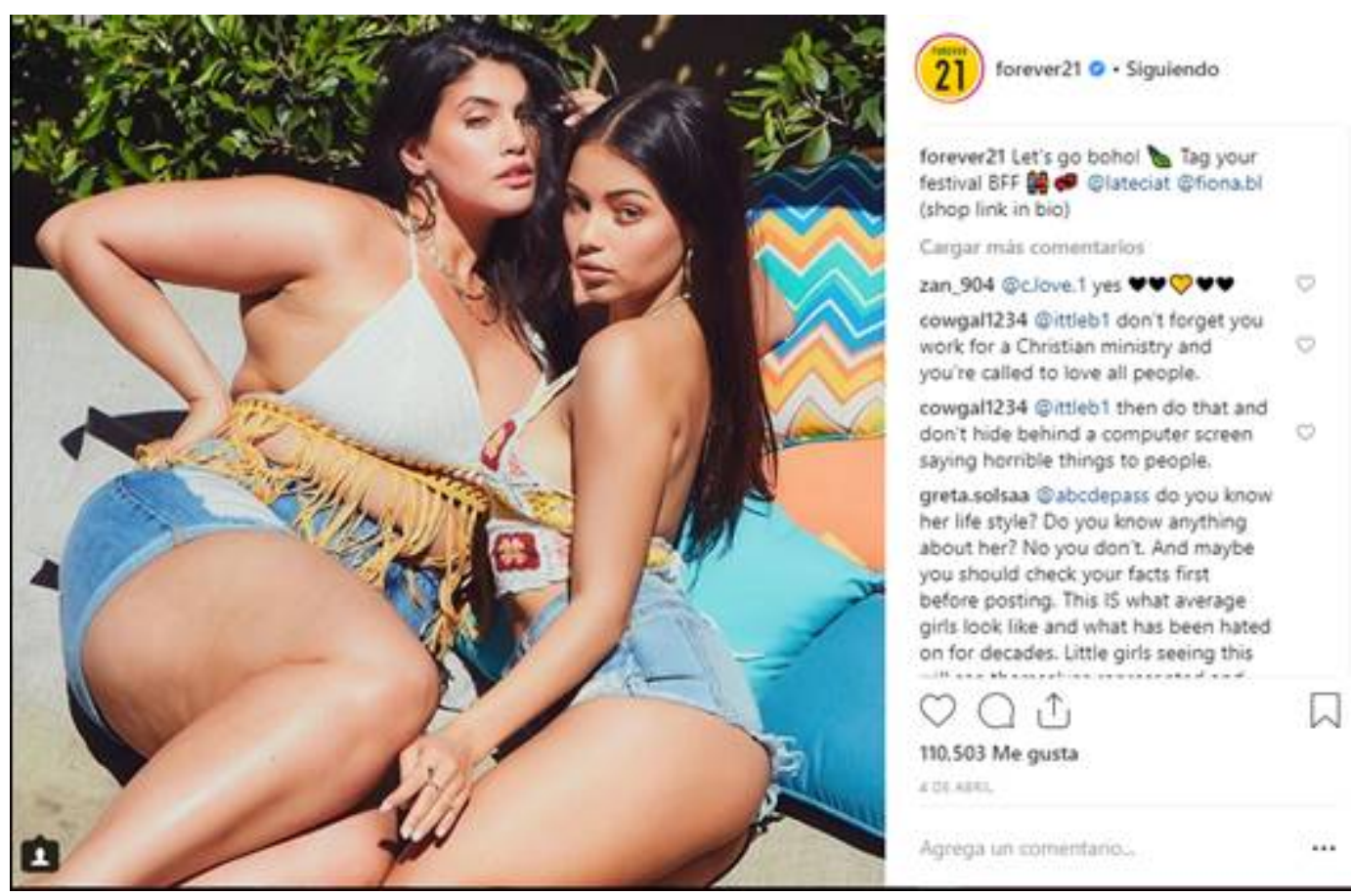

Foto 3: fotografía y mensaje publicitario publicados el 04 de abril de 2018, en la cuenta oficial de Instagram de la marca Forever 21.

Fuente: https://www.instagram.com/p/BhHWApaFEUn/?hl=es\&takenby=forever21 (consultado el 20.10.2018). 


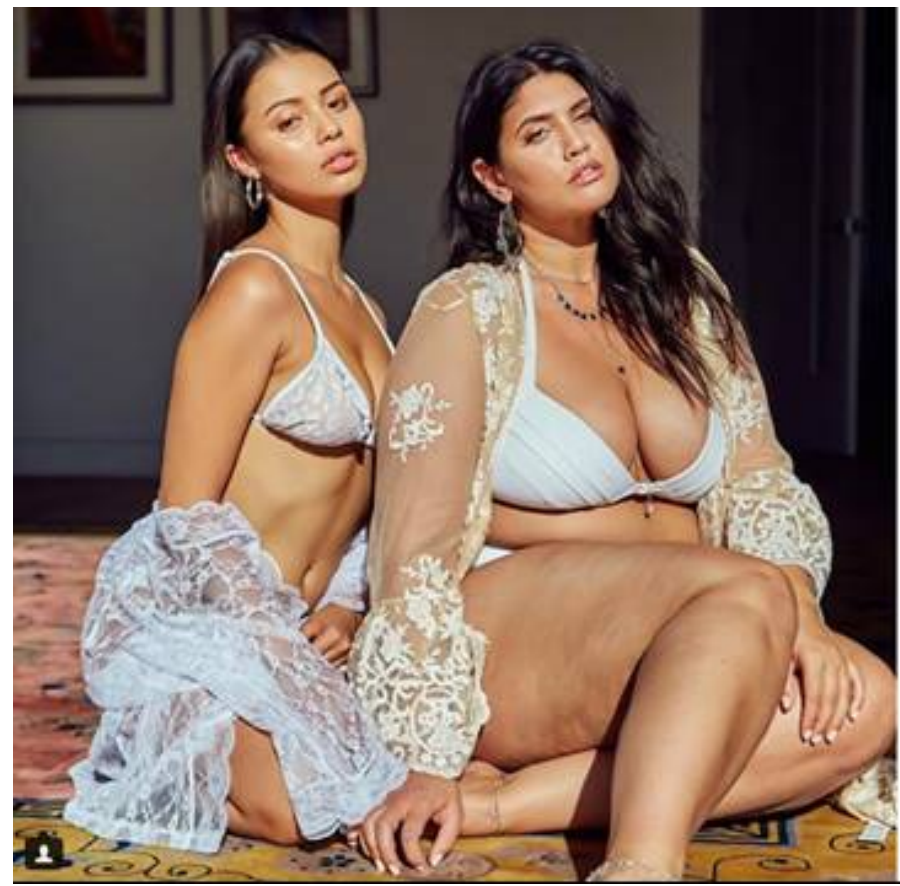

(21) forever21 $0 \cdot$ Siguiendo

forever21 Girl's night in \& \&fiona.b (1)iateciat (shop link in bio)

Cargar más comentarios

mother nature 17 . Froncruse being healthy simply means your body

functions the way it's supposed to. and without asking her, there's no way of knowing if she has medical issues, stop judging.

yamilanoe20 Reallyyyy?? Come onnine

vanyarea Evarramutiara

katiuskabarbozat Secpintopaz h

mother nature 17 Qalicedmorgan eh. stop being so damn ignorant (2) justicelutz @mother_nature_17_ Not gnorant I just know that she's well over the hesithy weioht and orobablv

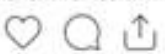
150.997 Me gusta oberast

Foto 4: fotografía y mensaje publicitario publicados el 06 de abril de 2018, en la cuenta oficial de Instagram de la marca Forever 21.

Fuente: https://www.instagram.com/p/BhHWApaFEUn/?hl=es\&takenby=forever21 (consultado el 20.10.2018).

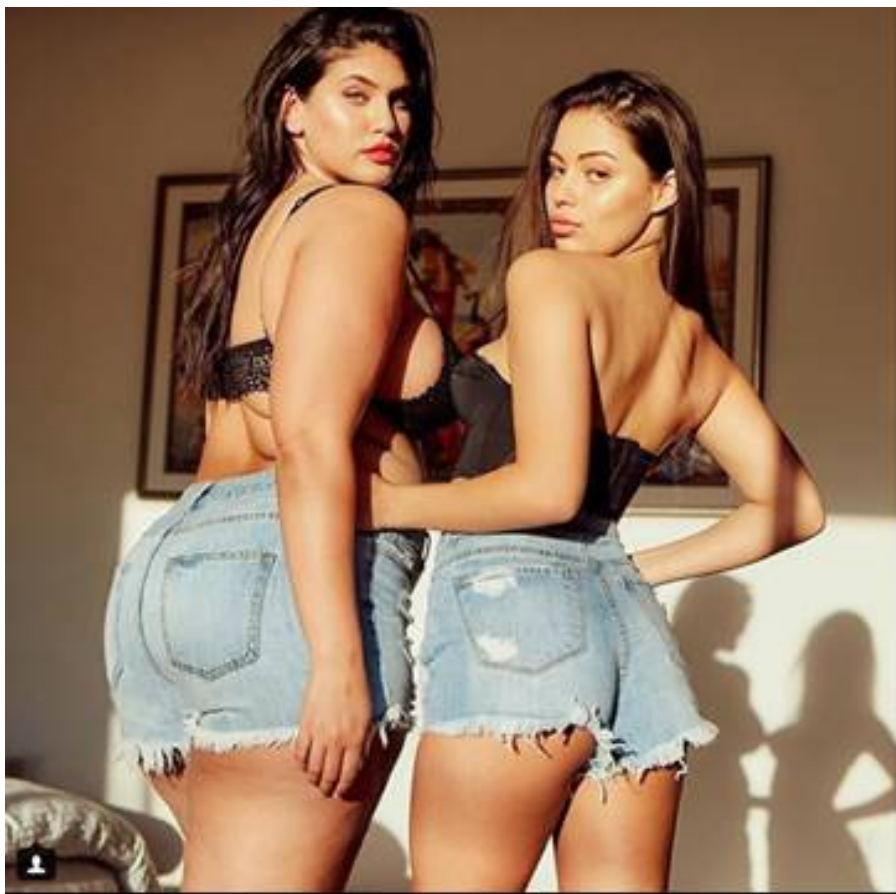

(21) forever $210 \cdot$ Siguiendo

forever 21 Look back at it $\mathbf{8} \&$ Q iatecia Qfiona.bI (shop link in bio) Cargar mas comentarios

dianabee_ Đoayerdi tu "creador" created them so how about you take your own advice and "reconoce is grandesa' that he has created. Hypocrite.

pradeepkamble 3407 Good evening medam

akanksha.singhhh @askeedamie andreariosecosa \%monicabrech jaja qué pedo con la sombra? Es para "vender mas"?

monicabrech @iveraseca baia baia lomeli sofie Fallow me $\boldsymbol{\theta}$ and 1 fallow you

$\bigcirc \bigcirc \uparrow$

96,118 Me gusta

ror ant

Marnoa un comentario

Foto 5: fotografía y mensaje publicitario publicados el 08 de abril de 2018, en la cuenta oficial de Instagram de la marca Forever 21.

Fuente: https://www.instagram.com/p/BhHWApaFEUn/?hl=es\&takenby=forever21 (consultado el 20.10.2018). 


\section{CONCLUSIONES}

A través de las imágenes se puede llegar a la mente y a los corazones de los consumidores, para posteriormente obtener un reconocimiento de marca, lo que se llama técnicamente posicionamiento. Es por ello que en publicidad resulta importante realizar estudios sobre la interpretación de la imagen. Como indicaba Romero (2002), "en la comunicación visual, el proceso de comprensión implica una decodificación para extraer el significado conceptual de las estructuras de comunicación visual". Este proceso está condicionado culturalmente. Por ejemplo, el significado de los colores depende completamente de la cultura.

Como conclusiones generales del análisis hermenéutico, se puede mencionar que el papel de la mujer de talla grande en la publicidad de Instagram de la marca Forever 21, simbólicamente representa un tipo de cambio que va de la mano con empoderamiento adquirido por las mujeres. Ya no sólo se trata de exigir productos con los cuales estén conformes; también les importan contenidos con los cuales se sientan identificadas. Forever 21 tiene ventajas que provocan una aceptación inmediata por las mujeres de talla grande de nivel socioeconómico medio: ofrece variedad de diseño, tallas que se asemejan con la figura, así como prendas de moda y juveniles a precios accesibles. Sin embargo, la marca quiere la aceptación y posicionamiento transmitiendo igualdad e inclusividad, exponiendo a dos modelos con fisionomías diferentes de forma similar.

El principal motivo de la marca no es mostrar que vende prendas para mujeres de talla grande, sino exponer dos cuerpos femeninos con ropa similar para transmitir igualdad y complicidad. De esta forma, las consumidoras deben sentir que esa ropa queda bien en todos los cuerpos y podrán sentirse identificadas. Se podrá generar simpatía y empatía con la marca, porque las prendas lucen bien, de forma apropiada y juvenil. Forever 21 anuncia que vende ropa de talla grande, dando un mensaje con el cual las mujeres puedan sentirse seguras, cómodas y femeninas. Al mismo tiempo, la marca intenta eliminar en cierto grado el cliché de que a las mujeres robustas no les gusta enseñar sus carnes, poniendo modelos de talla grande con escotes pronunciados.

En cuanto a los elementos de la composición, se debe destacar que cuando el cuerpo de talla grande aparece del lado izquierdo y se genera equilibro y una composición más adecuada. Al ser Instagram una red social con características tipográficas estipuladas, todos los elementos de texto son iguales. Lo único que se modifica son los emojis. Otra característica importante es que la marca no utiliza hashtags, como sí hacen otras marcas, pero se vale de emojis como elementos visuales, llamativos y divertidos, para completar el mensaje.

Los planos son generales y americanos porque abarcan toda la figura o sólo de las piernas para arriba; mientras que ángulo contrapicado aparece en las imágenes para representar un personaje psíquicamente fuerte, dominante o superior. Por otro lado, la ropa, que este caso es el producto principal, comunica feminidad, juventud, estatus

Vivat Academia. Revista de Comunicación. 15 junio 2020 /15 septiembre 2020, nº 151, 1-24 
socioeconómico, personalidad, en qué clima se pueden usar y en qué situación. Sin embargo, lo que genera conversación en los comentarios no es el producto, sino las modelos, específicamente la modelo de talla grande, quien le otorga reconocimiento a la marca por mostrarse inclusiva, y quien al mismo tiempo es criticada de forma positiva y negativa por su aspecto físico.

Las dos modelos que aparecen en las imágenes intentan demostrar plena inclusión a través de la ropa, debido a que las prendas son muy parejas, con medidas diferentes adaptadas a cada tipo de cuerpo, pero con colores y texturas similares. Sin embargo, los comentarios de las usuarias reflejan que, si bien muchas mujeres se sienten identificadas al comentar que tienen cuerpos similares, la aceptación por parte de las seguidoras de Forever 21, y posibles consumidoras, no tiene la seriedad que necesita la marca, las usuarias aceptan que tienen cuerpos similares al de la modelo de talla grande, pero en forma de burla o con sarcasmo.

Para concluir, se reitera que la publicidad de la marca Forever 21 está intentando transmitir igualdad e integración a través de modelos de tallas grandes, pero, sobre todo, una nueva representación de la belleza que responde más a la fisionomía y realidad de las mujeres no sólo españolas, también norteamericanas y latinas.

\section{REFERENCIAS}

Almansa-Martínez, A. y Gómez de Travesedo-Rojas, R. (2017). El estereotipo de mujer en las revistas femeninas españolas de alta gama durante la crisis. Revista Latina de Comunicación Social, 72(6), 608-628. Recuperado de http://www.revistalatinacs.org/072paper/1182/RLCS-paper1182.pdf

Álvarez, I. (2016). La historia de Do Won Chang, el hombre detrás de Forever 21. Forbes. Recuperado de http://forbes.es/emprendedores/9567/la-historia-de-dowon-chang-el-hombre-detras-de-forever-21/

Amador Bech, J. (2008). El significado de la obra de arte. México, DF: UNAM.

Bernárdez, A. y Moreno, I. (2017). La maternidad contemporánea entre la catástrofe y el sacrificio. Un análisis de Lo imposible. L'Atalante: revista de estudios cinematográficos, (23), 171-186. Recuperado de

http:/ / revistaatalante.com/index.php?journal=atalante\&page $=$ article\&op $=v i e w \&$ path $\% 5 \mathrm{~B} \% 5 \mathrm{D}=378$

Bernárdez, A. \& Padilla, G. (2018). Mujeres cineastas y mujeres representadas en el cine comercial español (2001-2016). Revista Latina de Comunicación Social, (73), 1247 1266. Recuperado de

https:/ / dialnet.unirioja.es/servlet/articulo?codigo $=6510246$.

Bernárdez, A. y Serrano, M. (2018). Lo personal es político. Un bebé en la sesión de constitución de las Cortes Generales. El tratamiento televisivo del caso de Carolina 
Las representaciones de la mujer de talla grande en la publicidad: caso Forever 21

Bescansa y su hijo. Vivat Academia, (142), 79-96. Recuperado de http:// www.vivatacademia.net/index.php/vivat/article/view/1086

Bernárdez, A. (2015). Mujeres en medio(s): propuestas para analizar la comunicación masiva con perspectiva de género. Madrid: Fundamentos.

Cabrera García-Ochoa, Y. (2010). El cuerpo Femenino en la Publicidad. Revista Icono 14, (8), 223-243. Recuperado de http://icono14.net/ojs/index.php/icono14/article/viewFile/236/113

Cuevas Barnerousse, T. (2009). Cuerpo, Feminidad y Consumo: El caso de jóvenes universitarias. Revista de Ciencias Sociales, (123-124), 79-92. Recuperado de http://www.redalyc.org/pdf/153/15313756005.pdf

Dondis, D. A. (1973). La sintaxis de la imagen. Barcelona: Gustavo Gili.

El Mercurio (2015). La historia de las Tallas grandes en la moda. El Mercurio. Economía y Negocios. Recuperado de http:// www.economiaynegocios.cl/noticias/noticias.asp?id=143983

Espizua, I. y Padilla, G. (2017). La imagen y el estilo de la mujer política española como elementos básicos de su comunicación. Revista de la SEECI, (42), 62-84. Recuperado de http://www.seeci.net/revista/index.php/seeci/article/view/453

Feijoo Fernández, B. y Guerrero, J. J. (2018). La investigación de mercados en redes sociales: conoce a tu consumidor por lo que publica en Facebook y Twitter. Análisis de cado de ADT Security Services en Chile. Vivat Academia. Revista de Comunicación, (144), 19-35. Recuperado de http://www.vivatacademia.net/index.php/vivat/article/view/1073/1409

García Calderón, C. (2015). Entre la tradición y la modernidad. Las identidades femeninas en las revistas mexicanas. México, DF: Leea Editorial.

Hernández Suriano, S. Z. (2013). Las representaciones de la mujer joven en la publicidad: análisis hermenéutico de la publicidad dirigida a los mercados Lifewife y Single en la revista femenina Glamour México. (Tesis inédita de licenciatura). UNAM-FCPyS, México.

Jivkova, D.; Requeijo, P. y Padilla, G. (2017). Usos y tendencias de Twitter en la campaña a elecciones generales españolas del 20D de 2015: hashtags que fueron trending topic. El profesional de la información, 26(5), 824-837. Recuperado de http://www.elprofesionaldelainformacion.com/contenidos/2017/sep/05.pdf

Lipovetsky, G. (1999). La tercera mujer. Permanencia y revolución de lo femenino. Barcelona: Anagrama. 
Martín Casado, T. G. (2009). La mujer en la ficción publicitaria: "La cárcel de cristal". Universidad Complutense de Madrid. Recuperado de http:// www3.udg.edu/publicacions/vell/electroniques/congenere/2/comunica cions/Teresa\%20Gema\%20Martin\%20Casado.pdf

Mejía Llano, J. C. (2019). Estadísticas de Redes Sociales 2019: Usuarios de Facebook, Twitter, Instagram, YouTube, LinkedIn, WhatsApp y otros, Marketing Digital. Juan Carlos Mejía Llano Blog. Recuperado de

https://www.juancmejia.com/marketing-digital/estadisticas-de-redes-socialesusuarios-de-facebook-instagram-linkedin-twitter-whatsapp-y-otros-infografia/

Milenio Digital (2017). Ashley Graham, la modelo plus size que hace historia. Milenio Digital. Recuperado de http:// www.milenio.com/tendencias/ashley_graham-modelo_plus_sizehace historia-forbes-milenionoticias_0_1071493263.html?utm_source=Twitter\&utm_medium=Referral\&utm_t erm=Tendencias\&utm_campaign=Milenio

Mora, L. E. y Padilla, G. (2018). Ruptura de estereotipos de género en series españolas para adolescentes. De "El barco" a "Las chicas del cable" en clave transaccional. Revista de análisis transaccional y psicología humanista, (78), 7-26.

Núñez Jiménez, N.; Olarte Pascual, C. y Reinares Lara, E. M. (2008). Influencia de la publicidad en las tendencias sociales: una aproximación exploratoria al mercado publicitario español, en Pindado García, J. y Payne, G. (Coords.). Estableciendo puentes en una economía global (pp. 29-45). Recuperado de https://dialnet.unirioja.es/servlet/articulo?codigo $=2739138$

Ortiz García, P. (2017). El discurso sobre el emprendimiento de la mujer desde una perspectiva de género. Vivat Academia, (140), 115-129. Recuperado de http://www.vivatacademia.net/index.php/vivat/article/view/1038

Padilla, G. y Oliver, A. B. (2018). "Instagramers" e "influencers". El escaparate de la moda que eligen los jóvenes menores españoles. aDResearch: Revista Internacional de Investigación en Comunicación, (18), 42-59. Recuperado de https:// dialnet.unirioja.es/servlet/articulo?codigo $=6785190$

Padilla, G. y Semova, D. (2014). Pensar y comunicar la ciencia en femenino: notoriedad de las mujeres científicas en Internet. Revista Internacional de Investigación en Comunicación aDResearch, (10), 74-89. Recuperado de https://doi.org/10.7263/adresic-010-04

Padilla, G. (2016). El éxito de la serie de televisión española “El Ministerio del Tiempo" desde el Análisis Transaccional. Revista de análisis transaccional y psicología humanista, (74), 66-79. 
Pellicer Jordá, T. (2018). ¿Por qué una publicidad ética? Las campañas más polémicas. Vivat Academia, (142), 97-107. Recuperado de http:// www.vivatacademia.net/index.php/vivat/article/view/1005

Romero Servín, V. (2002). Mensajes publicitarios en revistas femeninas y su relación con la mujer mexicana en el umbral del siglo XXI. (Tesis inédita de maestría). UNAMFCPyS, México.

Sánchez, S. (2018). Estadísticas redes sociales 2018 en España. Concepto 05. Recuperado de https://www.concepto05.com/2018/07/estadisticas-redessociales-2018-en-espana/

Tapia, A. y Del Toro, A. (2019). Semidesnudo, género y otros factores en publicidad televisiva. Un acercamiento desde la neurociencia. Vivat Academia, (147), 1-21. Recuperado de

http://www.vivatacademia.net/index.php/vivat/article/view/1101

Tapia, A.; Rajas, M. y Martín, E. (2018). Diferencias de género en el consumo audiovisual: un experimento de neurociencia sobre spots de televisión. Vivat Academia, (141), 39-54. Recuperado de

http:// www.vivatacademia.net/index.php/vivat/article/view/1033/1348

Walzer, A. (2008). De la metafísica al spot. La belleza. Barcelona: Octaedro.

\section{AUTORA:}

\section{Noemi Vargas Ortiz}

Egresada en Ciencias de la Comunicación por la Facultad de Ciencias Políticas y Sociales (FCPyS) de la Universidad Nacional Autónoma de México (UNAM). Colaboradora en publicaciones para la UNAM como son los libros Rostros en la oscuridad: Cárceles y Oaxaca: Decodificación de tradiciones. Colaboradora en el portal México en Boga, en el área de comunicación social de la PROFEPA y en la consultora E.life. Esta investigación fue realizada bajo el Programa de Titulación para egresados de la UNAM a través de Estancia Académica en la Universidad Complutense de Madrid, España.

Orcid ID: https:/ / orcid.org/0000-0002-3252-2837

Google Scholar: https://scholar.google.es/citations?hl=es\&user=dKzg_G8AAAAJ 